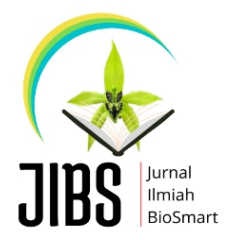

JURNAL ILMIAH BIOSMART (JIBS)

Volume 1, Nomor 1

p-ISSN: 2356-1822

https://jurnal.fkip.unmul.ac.id/index.php/biosmar .

\title{
KANDUNGAN MIKROPLASTIK PADA IKAN BAWIS (Siganus canaliculatus) DAN IKAN KEMBUNG (Rastrelliger kanagurta) DI PERAIRAN BONTANG
}

\author{
Muhammad Wawan Adisaputra ${ }^{1^{*}}$, Masitah ${ }^{1}$ dan Sri Purwati ${ }^{1}$ \\ 'Program Studi Pendidikan Biologi FKIP Universitas Mulawarman, Samarinda, Indonesia \\ *m.wawanadio71197@gmail.com
}

\begin{abstract}
Microplastic content in bawis fish (Siganus canaliculatus) and mackerel fish (Rastrelliger kanagurta) in Bontang waters. This study aims to determine the microplastic content of bawis fish (Siganus canaliculatus) and mackerel fish (Rastrelliger kanagurta) in Bontang waters. The sampling method was purposive sampling, that is, the sampling of data sources with certain considerations. The research sample of bawis fish (Siganus canaliculatus)) and mackerel (Rastrelliger kanagurta) found in Bontang sea waters. The results showed that there were microplastic content in bawis fish (Siganus canaliculatus) and mackerel fish (Rastrelliger kanagurta) with various types and sizes. The microplastics found in the bawis fish (Siganus canaliculatus) contained 57 particles of $>150 \mu \mathrm{m}$ in length and $11<150 \mu \mathrm{m}$ in length. Then mackerel fish (Rastrelliger kanagurta) contained 47 particles of $>150 \mu \mathrm{m}$ in length and 15 particles of $<150 \mu \mathrm{m}$ in length.
\end{abstract}

Key words: bawis fish (Siganus canaliculatus), mackerel fish (Rastrelliger kanagurta), microplastic.

\begin{abstract}
Abstrak Kandungan mikroplastik pada ikan bawis (Siganus canaliculatus) dan ikan kembung (Rastrelliger kanagurta) di perairan Bontang. Penelitian ini bertujuan untuk mengetahui kandungan mikroplastik pada ikan bawis (Siganus canaliculatus) dan ikan kembung (Rastrelliger kanagurta) di perairan Bontang. Metode pengambilan sampel dengan purposive sampling yaitu pengambilan sampel sumber data dengan pertimbangan-pertimbangan tertentu. Sampel penelitian ikan bawis (Siganus canaliculatus) dan ikan kembung (Rastrelliger kanagurta) yang terdapat di perairan laut Bontang. Hasil penelitian menunjukkan terdapat kandungan mikroplastik pada ikan bawis (Siganus canaliculatus) dan ikan kembung (Rastrelliger kanagurta) dengan berbagai macam jenis dan ukuran. Mikroplastik yang ditemukan pada sampel ikan bawis (Siganus canaliculatus) terdapat kandungan mikroplastik yang memiliki panjang >150 $\mu \mathrm{m}$ sebanyak 57 partikel dan panjang <150 $\mu \mathrm{m}$ sebanyak 11 partikel. Kemudian ikan kembung (Rastrelliger kanagurta) terdapat kandungan mikroplastik yang memiliki panjang >150 $\mu \mathrm{m}$ sebanyak 47 partikel dan panjang <150 $\mu \mathrm{m}$ sebanyak 15 partikel.
\end{abstract}

Kata kunci: ikan bawis, ikan kembung, mikroplastik

Penerbit

Program Studi Pendidikan Biologi, Fakultas Keguruan dan Ilmu Pendidikan, Universitas Mulwarman, Samarinda, Kalimantan Timur, Indonesia

This Jurnal Ilmiah Biosmart (JIBS) is licensed under a CC BY-SA (Creative Commons AttributionShareAlike 4.0 International License) 


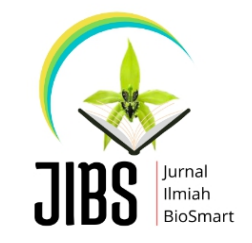

JURNAL ILMIAH BIOSMART (JIBS)

Volume 1, Nomor 1

p-ISSN: 2356-1823

https://jurnal.fkip.unmul.ac.id/index.php/biosmart

\section{PENDAHULUAN}

Perkembangan tentang isu sampah laut (Marine Debsris) memasuki babak baru ketika Indonesia dinobatkan menjadi negara kedua penyumbang sampah plastik ke laut dengan tingkat kepadatan penduduk ke-4 tertinggi setelah Amerika Serikat, India dan Tiongkok. Dikutip dari Purba, 2017: 1 menyatakan Indonesia merupakan negara kedua terbesar penyumbang sampah sebesar 3.2 juta ton. Indonesia hanya kalah dari negara Tiongkok di peringkat pertama. 192 negara pesisir (termasuk Indonesia), setidaknya sudah membuang sampah ke laut sebesar 12.7 juta ton dengan jumlah penduduk yang lebih sedikit dari India, negara tersebut masih jauh dibawah Indonesia dalam menyumbang sampah ke laut.

Plastik merupakan benda yang paling banyak digunakan oleh setiap manusia. Sifat plastik yang ringan, kuat dan mudah untuk dibawa memberikan kemudahan bagi manusia. Kegunaan bagi kehidupan sehari-hari seperti untuk pembungkus makanan, minuman, perabotan rumah tangga, bahan dasar dalam pembuatan pipa-pipa saluran air, alat transportasi, alat medis dan elektronik. Menurut Moore, dkk., (2004: 1) plastik merupakan material yang sangat stabil sehingga akan tetap berada dalam kondisi utuh sebagai polimer dalam jangka waktu yang lama.

Menurut data kementrian Lingkungan Hidup dan Kehutanan (KLHK), Indonesia menyebutkan jumlah rata-rata produksi sampah di Indonesia mencapai 175.000 ton per hari dan tercatat total sampah di tahun 2018 sebanyak 65,752 juta ton. Sampah-sampah kini tak hanya mencemari lingkungan darat, tetapi juga menjadi masalah di laut karena mencemari kebersihan laut.

Beberapa hal yang menyebabkan pencemaran di laut adalah dikarenakan kurangnya kesadaran masyarakat dalam membuang sampah pada tempatnya dan kurangnya pengetahuan masyarakat terhadap daur ulang sampah sehingga menyebabkan terjadinya penumpukan sampah organik dan anorganik yang diperparah tidak terpilah nya atau tercampur dan menambah jumlah sampah yang terbuang di lingkungan.

Sampah plastik yang terbuang kelingkungan akan menjadi bahan pencemar baru berupa mikroplastik. Plastik akan mengalami degradasi oleh alam yang akan membentuk partikel-partikel plastik yang tidak dapat dilihat secara kasat mata yang 


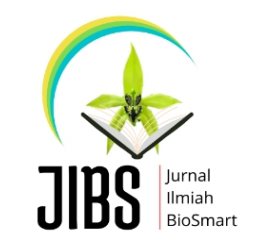

JURNAL ILMIAH BIOSMART (JIBS)

Volume 1, Nomor 1

p-ISSN: 2356-1823

https://jurnal.fkip.unmul.ac.id/index.php/biosmart

secara sengaja atau tidak sengaja akan termakan oleh biota air tawar dan air laut. Menurut Thompson, dkk., (2009: 1) proses terjadinya mikroplastik diawali ketika plastik terkoyak-koyak dan terdegradasi oleh sinar matahari (fotodegradasi), oksidasi, dan abrasi mekanik membentuk partikel-partikel plastik

Mikroplastik yang termakan oleh biota laut dapat menjadi ancaman bagi manusia. Ketika manusia memakan ikan yang terkontaminasi mikroplastik termasuk pada ikan bawis (Siganus canaliculatus) dan ikan kembung (Rastrelliger kanagurta). Menurut Sari, (2018: 56) menyatakan bahwa mikroplastik tidak terlihat secara kasat mata akan tetapi berpotensi memberi dampak negatif baik bagi biota maupun perairan.

Ikan bawis termasuk jenis ikan yang hidup di terumbu karang dan padang lamun. Ikan ini memiliki julukan yang berbeda-beda disetiap daerah. Dikota Bontang ikan ini kerap menjadi santapan andalan penduduk Bontang dan menjuarai ajang festival kuliner nasional. Menurut Turang, dkk., (2019: 194) ikan ini dikenal oleh masyarakat dengan nama yang berbeda-beda satu sama lain seperti di Pulau Seribu dinamakan kea-kea, di Jawa Tengah dengan nama biawas, dan nelayan-nelayan di Pulau Maluku menamakannya samadar.

Oktawati (2019: 249) menyatakan luas lamun di Kota Bontang mencapai 13.990,8 ha dan tersebar hampir di seluruh bagian pesisir dan pulau-pulau Kota Bontang. Ekosistem padang lamun menjadi tujuan utama penangkapan ikan bawis (Siganus canaliculatus). Ikan bawis termasuk ikan endemik lamun yang banyak ditemukan di Kota Bontang, Kalimantan Timur. Keberadaan ikan bawis mempunyai peran penting dalam menjaga kestabilan ekosistem padang lamun.

Ikan kembung merupakan salah satu jenis ikan ekonomi penting di kota Bontang melihat banyaknya nelayan yang menangkap serta di konsumsi oleh masyarakat. Menurut Puspitasari (2013: 8) dan Susanti, dkk (2019: 46) ikan kembung merupakan kelompok ikan epipelagis dan neritic didaerah pantai dan laut. Ikan ini mempunyai nilai gizi yang tinggi dan nilai ekonomis menengah, sehingga menyebabkan nelayan terus menerus melakukan penangkapan untuk memenuhi permintaan konsumen domistik yang tinggi. 

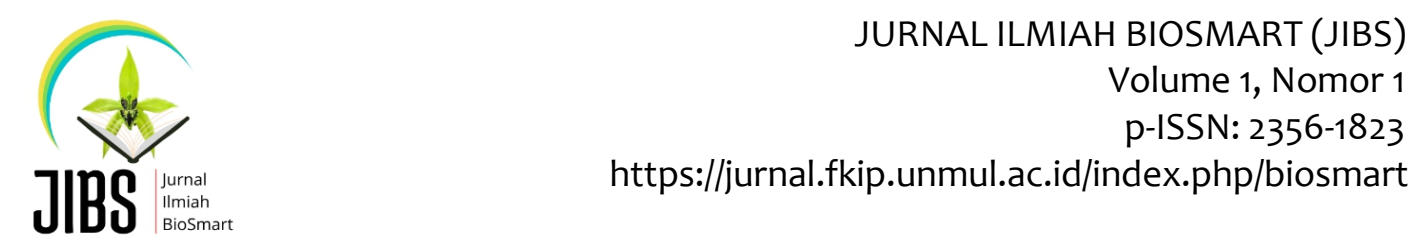

Karena banyaknya orang yang mengonsumsi ikan bawis dan ikan kembung hasil menjaring di perairan Bontang ataupun yang membeli ikan di pasar serta kurangnya pengetahuan tentang mikroplastik yang mungkin berada di dalam tubuhnya Ikan tersebut sehingga dapat termakan oleh manusia. Oleh sebab itu, penulis melakukan penelitian "Kandungan mikroplastik pada ikan bawis (Siganus canaliculatus) dan ikan kembung (Rastrelliger kanagurta) di perairan Bontang.

\section{METODE}

Jenis penelitian yang digunakan oleh peneliti adalah penelitian kualitatif, dengan metode analisis deskriptif untuk mengetahui dan menggambarkan partikelpartikel mikroplastik yang ditemukan pada ikan bawis (Siganus canaliculatus) dan ikan kembung(Rastrelliger kanagurta) di perairan Bontang.

Penelitian ini dilaksanakan selama tiga bulan. Dalam proses pengambilan data dilakukan dengan purposive sampling. Menurut Sugiyono (2016: 85) menyatakan purposive sampling yaitu pengambilan sampel sumber data dengan pertimbanganpertimbangan tertentu. Lokasi pengambilan sampel ikan bawis di perairan laut Bontang dekat dengan Bontang Kuala sedangkan ikan kembung berlokasi di laut lepas wilayah Kecamatan Bontang Utara. Alat yang digunakan untuk menangkap ikan bawis dan ikan kembung dengan menggunakan alat tangkap jaring.

\section{Alat dan Bahan}

Alat yang digunakan adalah pisau bedah, gelas beaker, spatula, timbangan analitik, gelas beaker, labu erlenmeyer, pipet tetes, pipet ukur, alu, mortar, aluminium foil, kaca preparat, oven dan mikroskop. Bahan yang digunakan adalah aquades, padatan $\mathrm{NaCl}$ dan isi saluran pencernaan dari ikan bawis (Siganus canaliculatus) dan ikan kembung(Rastrelliger kanagurta)

\section{Prosedur Penelitian}

Langkah-langkah yang dilakukan saat penelitian adalah:

1. Persiapan Sampel

2. Pembedahan Ikan 


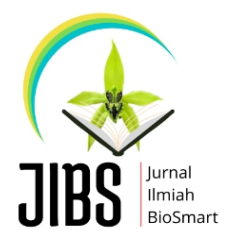

JURNAL ILMIAH BIOSMART (JIBS)

Volume 1, Nomor 1

p-ISSN: 2356-1823

https://jurnal.fkip.unmul.ac.id/index.php/biosmart

3. Pengambilan isi dari saluran pencernaan (kerongkongan hingga kloaka), yang kemudian dikeringkan

4. Pembuatan larutan $\mathrm{NaCl}$ jenuh

5. Sampel yang telah kering dimasukkan pada larutan $\mathrm{NaCl}$ jenuh, lalu ditunggu selama 20 menit

6. Diambil bagian yang mengapung di permukaan untuk identifikasi melalui pengamatan mikroskop

\section{HASIL PENELITIAN}

A. Gambaran Umum Lokasi Penelitian

Penelitian dilakukan di Kota Bontang yang berjarak 150 km dari kota Samarinda, Kalimantan Timur. Secara astronomis, Kota Bontang berada dalam posisi $117^{\circ} 23^{\prime}-117^{\circ}$ 38' Bujur Timur, serta $0^{\circ} 01^{\prime}-0^{\circ} 14^{\prime}$ Lintang Utara yang terbagi menjadi 3 Kecamatan yaitu Bontang Selatan, Bontang Utara dan Bontang Barat.

Lokasi penangkapan ikan bawis (Siganus canaliculatus) didominasi oleh padang lamun. Tranportasi ke lokasi penangkapan menggunakan perahu pada pukul 10.00 WITA dengan waktu tempuh 1 jam dengan jarak 5,6 km. Lokasi ini berdekatan dengan kampung air Bontang Kuala. Bontang kuala merupakan salah satu pemukiman di atas air dan menjadi objek wisata yang paling banyak dikunjungi di Kota Bontang.

Lokasi penangkapan ikan kembung (Rastrelliger kanagurta) berada dilaut lepas. Transportasi ke lokasi penangkapan menggunakan perahu pada pukul 05.00 WITA dengan waktu tempuh kurang lebih 2 jam dengan jarak 9,5 km. Adapun titik lokasi penangkapanberada di wilayah Kecamatan Bontang Utara. Selama perjalanan dan juga dilokasi penangkapan banyak terdapat botol plastik, sterofoam, kantong plastik dan jerigen yang mengapung. 
Adapun hasil perhitungan yang ditampilkan pada tabel dan bagan berikut.

Tabel 1. Rekapitulasi Perhitungan Ukuran, dan Jumlah Mikroplastik pada Ikan Bawis (Siganus canaliculatus)

\begin{tabular}{|c|c|c|c|c|c|c|}
\hline \multirow[b]{2}{*}{ Sampel } & Jumlah & Jumlah & Jumlah & Jumlah & Jumlah & \multirow{2}{*}{$\begin{array}{c}\text { Rata-rata } \\
\text { Panjang } \\
(\mu \mathrm{m})\end{array}$} \\
\hline & Fragmen & Fiber & Film & Monofilament & Keseluruhan & \\
\hline Bw1 & 8 & 3 & 5 & - & 16 & 471.18 \\
\hline $\mathrm{Bw} 2$ & 4 & 4 & 3 & 3 & 14 & 354.28 \\
\hline Bw3 & 6 & 3 & 2 & 2 & 13 & 293.85 \\
\hline Bw4 & 6 & 3 & 1 & 3 & 13 & 429.23 \\
\hline Bw5 & 4 & 3 & 5 & - & 12 & 275.83 \\
\hline
\end{tabular}

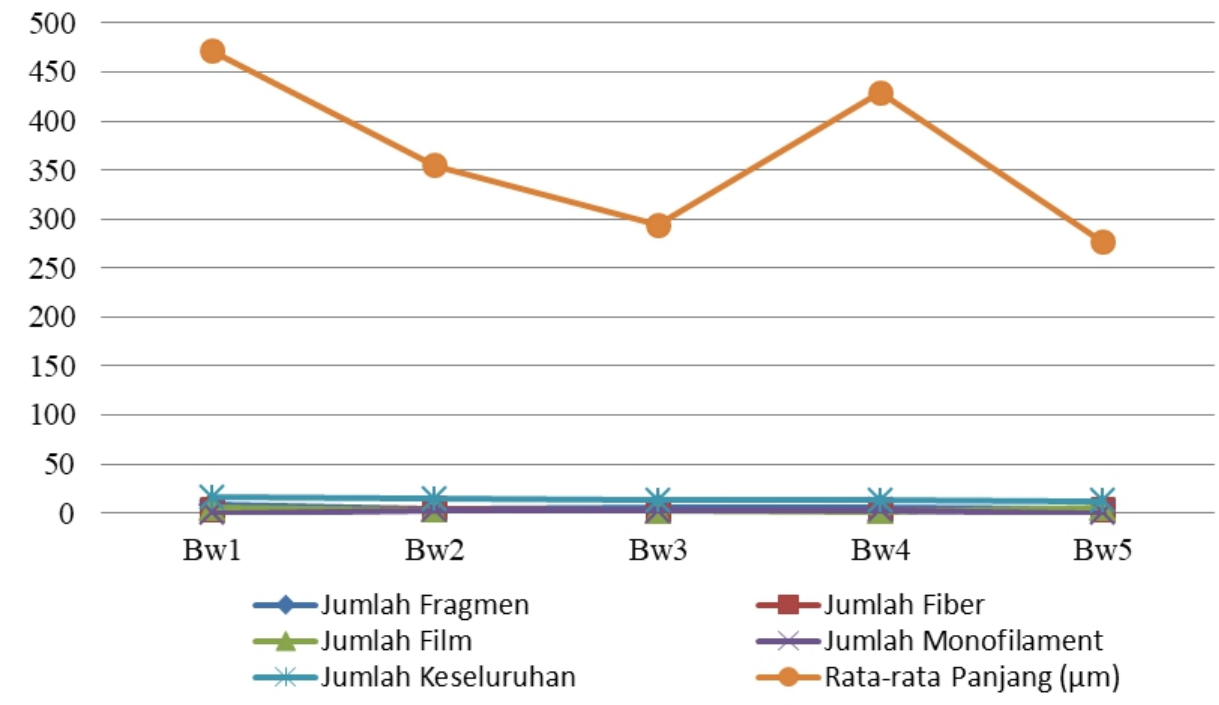

Gambar 1. Grafik ukuran dan jumlah mikroplastik pada ikan bawis

Tabel 2. Rekapitulasi Perhitungan Ukuran, dan Jumlah Mikroplastik pada Kembung (Rastrelliger kanagurta) 


\begin{tabular}{|c|c|c|c|c|c|c|}
\hline \multirow[t]{2}{*}{ Sampel } & Jumlah & Jumlah & Jumlah & Jumlah & Jumlah & \multirow{2}{*}{$\begin{array}{c}\text { Rata-rata } \\
\text { Panjang } \\
(\mu \mathrm{m})\end{array}$} \\
\hline & Fragmen & Fiber & Film & Monofilament & Keseluruhan & \\
\hline $\mathrm{Kb}_{1}$ & 4 & 2 & 8 & - & 14 & 302.14 \\
\hline $\mathrm{Kb}_{2}$ & 6 & 1 & 5 & - & 12 & 285 \\
\hline $\mathrm{Kb}_{3}$ & 3 & - & 2 & 6 & 11 & 252.72 \\
\hline $\mathrm{Kb} 4$ & 5 & - & 5 & 4 & 14 & 414.28 \\
\hline Kb5 & 5 & - & 5 & 1 & 11 & 264.54 \\
\hline
\end{tabular}

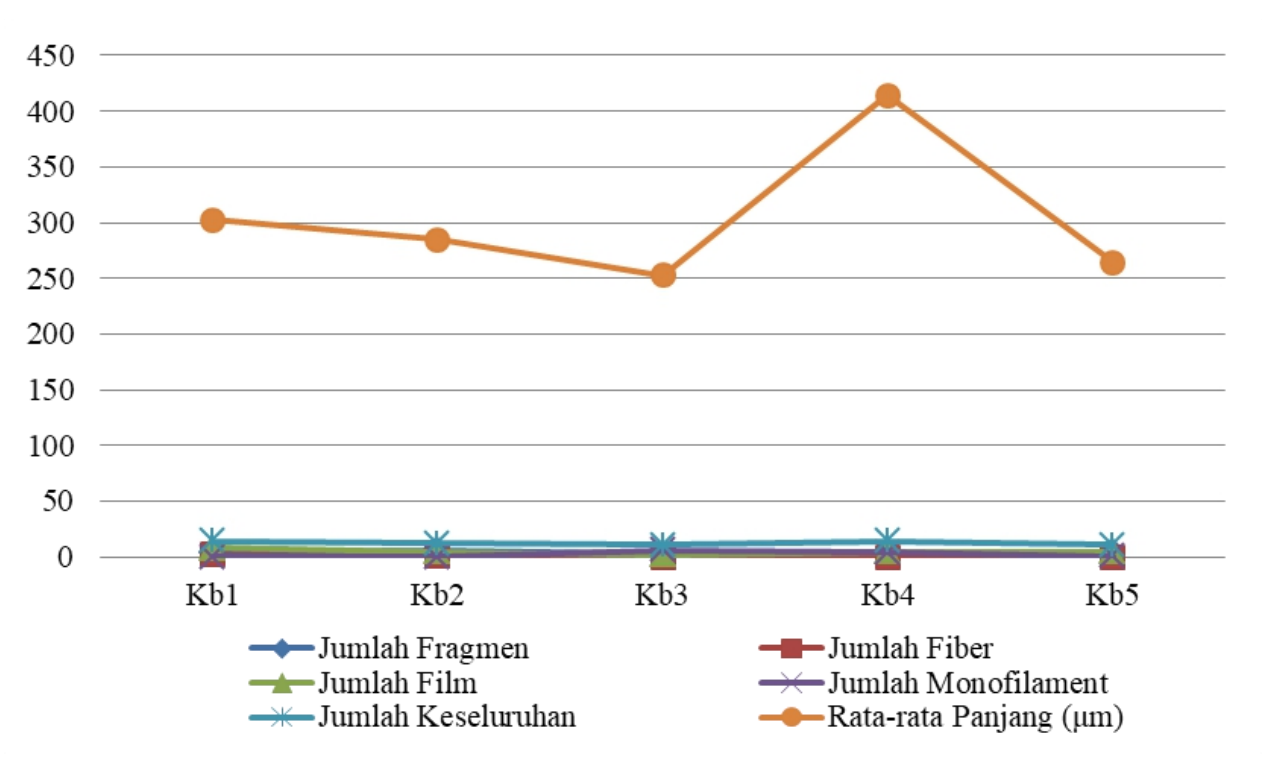

Gambar 2. Grafik ukuran dan jumlah mikroplastik pada ikan bawis

\section{PEMBAHASAN}

Ikan bawis (Siganus canaliculatus) yang berasal dari perairan laut Kota Bontang ditemukan jumlah mikroplastik sebanyak 68 partikel yang didominansi oleh 28 partikel fragmen, 16 partikel fiber, 16 partikel film dan 8 partikel Monofilament. Pada Bw1 berjumlah 16 partikel dengan panjang rata-rata $=471.18 \mu \mathrm{m}$, Bw2 terdapat 14 partikel dengan panjang rata-rata $=354.28 \mu \mathrm{m}$, Bw3 terdapat 13 partikel dengan panjang rata-rata $=293.85 \mu \mathrm{m}$, Bw4 terdapat 13 partikel dengan panjang rata-rata= $429.23 \mu \mathrm{m}$, dan Bw5 terdapat 12 partikel dengan panjang rata-rata= $275.83 \mu \mathrm{m}$. Maka dapat ditentukan rata-rata ukuran panjang dari kelima sampel tersebut adalah 364.87 $\mu \mathrm{m}$. 


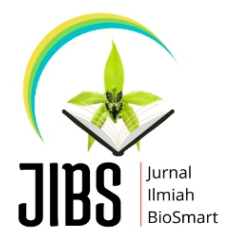

JURNAL ILMIAH BIOSMART (JIBS)

Volume 1, Nomor 1

p-ISSN: 2356-1823

https://jurnal.fkip.unmul.ac.id/index.php/biosmart

Ikan kembung (Rastrelliger kanagurta) yang berasal dari perairan laut Kota Bontang ditemukan jumlah mikroplastik sebanyak 62 partikel yang didominansi oleh 23 partikel Fragmen, 3 partikel Fiber, 25 partikel Film dan 11 partikel Monofilament. Pada Kb1 berjumlah 14 partikel dengan panjang rata-rata $=302.14 \mu \mathrm{m}$, Kb2 terdapat 12 partikel dengan panjang rata-rata $=285.00 \mu \mathrm{m}, \mathrm{Kb} 3$ terdapat 11 partikel dengan panjang rata-rata $=252.72 \mu \mathrm{m}, \mathrm{Kb} 4$ terdapat 14 partikel dengan panjang rata-rata $=$ $414.28 \mu \mathrm{m}$, dan $\mathrm{Kb} 5$ terdapat 11 partikel dengan panjang rata-rata $=264.54 \mu \mathrm{m}$. Maka dapat ditentukan rata-rata ukuran panjang dari kelima sampel tersebut adalah 303.73 $\mu \mathrm{m}$.

Berdasarkan hasil perhitungan pada ikan bawis ditemukan 57 partikel yang berukuran >150 $\mu \mathrm{m}$ dan 11 partikel yang berukuran <150 $\mu \mathrm{m}$. Sedangkan pada ikan kembung ditemukan 47 partikel yang berukuran >150 $\mu \mathrm{m}$ dan 15 partikel yang berukuran <150 $\mu \mathrm{m}$. Menurut Lusher (2017: 60) ukuran panjang partikel mikroplastik berada pada ukuran rata-rata $>150 \mu \mathrm{m}$ yang artinya tidak diserap karena melalui sistem imun dan respon inflamasi dan ukuran $<150 \mu \mathrm{m}$ mengalami proses penyerapan di limpa $\leq 0,3 \%$.

Sejauh ini belum ada penelitian lebih lanjut terkait dampak dari banyaknya jumlah partikel dan batasan maksimal yang ditentukan. Menurut Lusher (2017: 59) menyatakan bahwa interaksi sistem imun dan mikroplastik atau nanoplastik menyebabkan imunotoksisitas dan mungkin dikaitkan dengan beberapa efek samping yaitu penurunan resistensi pembawa terhadap agen infeksi dan tumor, aktivasi kekebalan tubuh (peningkatan risiko alergi dan autoimun penyakit), dan respons inflamasi abnormal. Namun, efek tersebut sejauh ini belum ada laporan yang terjadi pada manusia.

Hapitasari (2016: 1) menyatakan bahwa apabila partikel plastik terakumulasi dalam jumlah yang besar dalam tubuh ikan, maka mikroplastik itu bisa menyumbat saluran pencernaan ikan menganggu proses-proses pencernaan ataupun menghalangi proses penyerapan.

Berdasarkan jenis mikroplastik yang paling banyak ditemukan dari ikan bawis dan ikan kembung adalah fragmen. Hal ini menandakan bahwa ikan tersebut diambil 

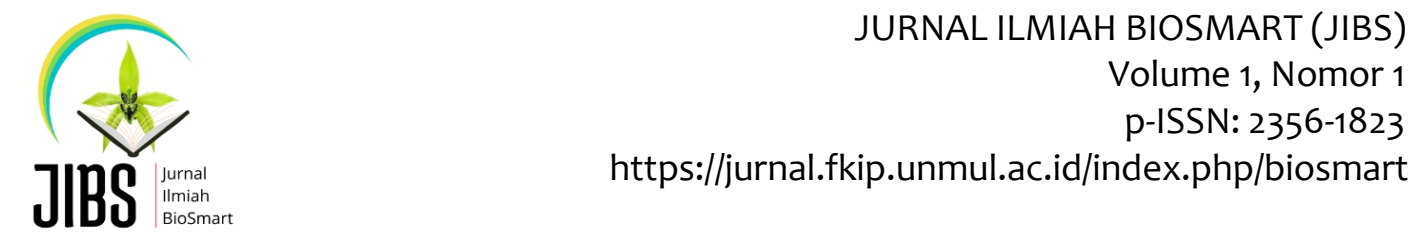

dari lingkungan atau ekosistem yang telah tercemar dengan kantong plastik, kemasan makanan, botol plastik, sedotan, gelas plastik dan sampah plastik lainnya.

Mikroplastik jenis fragmen berbentuk pecahan atau patahan dari plastik yang lebih besar, beraturan dan lebih tebal. Menurut Dewi (2015: 128) mikroplastik jenis fragmen berasal dari pertokoan atau warung makanan antara lain kantong kantong plastik yang berukuran besar atau kecil, kemasan makanan siap saji dan botol minuman plastik. Sampah plastik tersebut terurai menjadi serpihan-serpihan kecil hingga membentuk fragment.

Mikroplastik jenis fiber di temukan di ikan bawis dan ikan kembung sebanyak 3 partikel. Fiber berbentuk seperti benang tipis serta memanjang. Menurut Sari (2018: 6) bahwa fiber merupakan hasil degradasi dari alat tangkap nelayan berupa tali, pakaian hingga karung plastik yang berasal dari pemukiman penduduk yang berada di daerah pesisir dengan sebagian besar masyarakat yang bekerja sebagai nelayan.

Mikroplastik jenis monofilament ditemukan pada semua jenis ikan. Berbentuk seperti untaian benang transparan, tipis, memanjang dan ujungnya bercabang Menurut Sari (2018: 6) dan Lusher (2017: 276) bahwa monofilament merupakan plastik yang bersumber dari jaring ikan nelayan, tali, kain sintetis dan limbah cucian. Monofilament ketika terfragmentasi akan menjadi fiber yang dapat menyumbang debris kedalam air laut. Bentuk dan ukuran nya yang tipis menyebabkan sering ditemukan mengambang dipermukaan air.

Mikroplastik jenis film ditemukan pada semua jenis ikan. Berbentuk seperti pecahan benda, tipis dan transparan yang berasal dari kantong plastik atau kemasan plastik. Menurut Sari (2018: 6) bahwa film merupakan polimer plastik sekunder yang berasal dari fragmentasi kantong plastik atau plastik kemasan dan memiliki densitas rendah dibanding dengan tipe mikroplastik lainnya. Jenis partikel mikroplastik yang ditemukan terdapat pada gambar 3. 


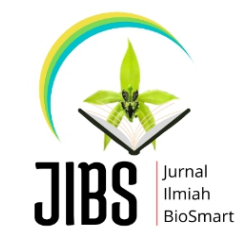

JURNAL ILMIAH BIOSMART (JIBS)

Volume 1, Nomor 1

p-ISSN: 2356-1823

https://jurnal.fkip.unmul.ac.id/index.php/biosmart

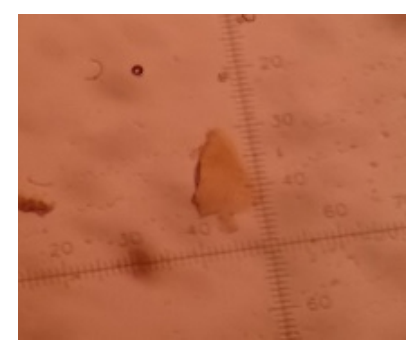

a.

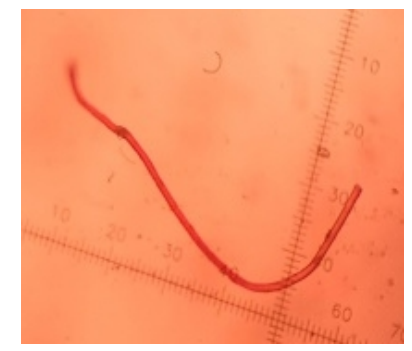

C.

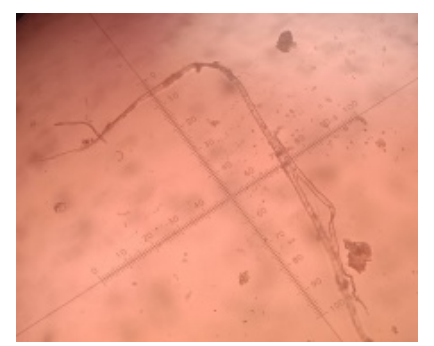

b.

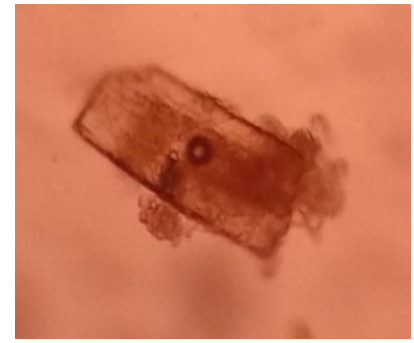

d.

Gambar 3. Bentuk partikel (a) film, (b) monofilament, (c) fiber, (d) fragmen

\section{KESIMPULAN}

Berdasarkan hasil penelitian dapat disimpulkan terdapat mikroplastik pada ikan bawis (Siganus canaliculatus) dan ikan kembung (Rastrelliger kanagurta). Jumlah mikroplastik pada ikan bawis yang memiliki panjang $>150 \mu \mathrm{m}$ sebanyak 57 partikel dan mikroplastik yang memiliki panjang <150 $\mu$ m sebanyak 11 partikel. Pada Ikan Kembung (Rastrelliger kanagurta) terdapat mikroplastik yang memiliki panjang $>150 \mu \mathrm{m}$ sebanyak 47 partikel dan mikroplastik yang memiliki <dari $150 \mu \mathrm{m}$ sebanyak 15 partikel. Jenis mikroplastik yang ditemukan yaitu fragmen, film, monofilament dan fiber.

\section{REFERENSI}

Dewi, Sari I., et all. 2015. Distribusi mikroplastik pada sedimen di Muara Badak. Jurnal Depik. Vol 4 (3): 121-131.

Hapitasari, D.N. 2016. A. Analisis Kandungan Mikroplastik pada Pasir dan Ikan Demersal: Kakap (Lutjanus sp.) dan Kerapu (Epinephelus sp.) di Pantai Ancol, Palabuhanratu, dan Labuan.

Lusher A. L., et all 2013. Occurrence of microplastic in the gastrointestal tract of pelagic and demersal fish from the English Channel. Marine Pollution Bulletin. Vol 67: 94-99. 


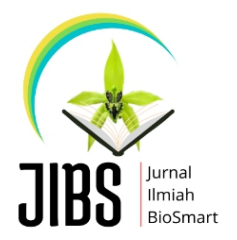

JURNAL ILMIAH BIOSMART (JIBS)

Volume 1, Nomor 1

p-ISSN: 2356-1823

https://jurnal.fkip.unmul.ac.id/index.php/biosmart

Lusher A. L., et all. 2017. Microplastic in Fisheries and Aquaculture. Rome: Food And Agriculture Organization Of The United Nations

Moore., et all. 2014. Plastic Pollution in the World's Oceans: More than 5 Trillion Plastic Pieces Weighing over 250,000 Tons Afloat at Sea PloS One. https://doi.org/101371/journalpone 0111913.

Oktawati, N. F., et all. 2019. Analisis Degradasi dan Depresiasi Sumberdaya Ikan Bawis (Siganus canaliculatus) di Perairan Kota Bontang. Jurnal EnviroSciante Vol 15 (2): $249-256$

Purba, N. P. 2017. Status Sampah Laut Indonesia. http://Indosmarin.com/StatusSampah-Laut-Indonesia.

Puspitasari, A. F. 2013. Identifikasi dan Prevalensi cacing Ektoparasit Pada Ikan Kembung (Rastre Elliger sp) di Pelabuhan Perikanan Nusantara Brondong Lamongan.

Sari, K. 2018. Keberadaan Mikroplastik pada Hewan Filter Feeder di Padang Lamun Kepulauan Spermonde Kota Makassar.

Sugiyono. 2016. Metode Penelitian Kuantitatif, Kualitatif dan Kombinasi (Mixed Methods). Bandung: Alfabeta.

Susanti, E., et all. 2019. Studi Aspek Reproduksi Ikan Kembung Lelaki (Rastrelliger Kanagurta, Cuvier 1817) Pada Musim Peralihan Di Selat Madura. Jurnal Bawal Widya Riset Perikanan Tangkap. Vol 11 (1): 45.

Thompson R. C., et all. 2009. Study On Structural, Mechinical and Functinal Properties of Polyester Silica Nanocomposite Fabric. Journal Or Pure and Appllied Sciences and Technology. Vol 21 (1).

Turang, R., et all. 2019. Struktur Ukuran, Pola Pertumbuhan dan Faktor Kondisi Ikan Baronang (Siganus canaliculatus) dari Perairan Teluk Totok Kecamatan Ratatotok Kabupaten Minahasa Tenggara. Jurnal Ilmiah Platax. Vol 7 (1): 193201. 